\title{
PAPEL SEMENTE: ATIVIDADE PEDAGÓGICA AMBIENTAL COMO PRINCÍPIO EDUCATIVO EM UMA ESCOLA DO CAMPO
} $\overline{\overline{\bar{c}}}$

\author{
SEED PAPER: ENVIRONMENTAL PEDAGOGICAL ACTIVITY \\ AS AN EDUCATIONAL PRINCIPLE IN A RURAL SCHOOL
}

\author{
Francieli Luana Sganzerla* \\ ORCID: https://orcid.org/0000-0002-7022-1525 \\ Fernanda Tarouco Gonçalves** \\ ORCID: https://orcid.org/0000-0003-0345-2910 \\ Ana Luiza Zappe Desordi Flôres*** \\ ORCID: https://orcid.org/0000-0001-9614-1710 \\ Aniara Ribeiro Machado**** \\ ORCID: https://orcid.org/0000-0001-8338-123X \\ Cadidja Coutinho***** \\ ORCID: https://orcid.org/0000-0002-5182-7775
}

Data recebimento: $07 / 05 / 2020$ 09/03/2021

\begin{abstract}
Resumo
O modo de vida pós-moderno tem trazido efeitos deletérios à saúde dos ecossistemas. Há muito tempo beiramos os limites saudáveis de produção e consumo, tornando necessárias propostas educativas que promovam cuidados com o meio ambiente nos mais diferentes contextos, principalmente no ambiente escolar. E quando a educação converge com a vida próxima ao meio, como é o caso do sujeito que vive no campo, favorece a realização de atividades das boas práticas de cuidado com a natureza. Sendo assim, este trabalho apresenta um relato de experiência de uma atividade que visou a produção de "Papel Semente" por alunos da educação básica de uma escola pública do campo de Santana do Livramento/RS. A prática pedagógica aqui relatada teve como finalidade incentivar a reciclagem, o desenvolvimento sustentável e o protagonismo do jovem do campo, a partir da produção de papel reciclado em sala de aula. Pode-se concluir que, no transcorrer da atividade, os alunos foram sensibilizados quanto às questões ambientais e mostraram-se motivados com a proposta pedagógica de Educação Ambiental.
\end{abstract}

Palavras chave: Educação ambiental; Reaproveitamento de papel; Educação do campo.

\begin{abstract}
Post-modern life has caused harmful effects to ecosystems health. The limit between healthy production and consumption has been at risk which calls for educational proposals that promote environmental care in diverse contexts, especially in the school environment. When education spaces are close to the environment, as is the case of those who live in the countryside, there is the opportunity to develop practices concerning the care for nature. Thus, this paper presents an experience report of an activity aimed at the production of Seed Paper by students of basic education of a public school in the countryside of Santana do Livramento/RS. The pedagogical practice intended to encourage recycling, sustainable development and the role of young people in the countryside, based on the production of recycled paper in the classroom. It was observed that the activity contributed to raise students' awareness about environmental issues as well as their motivation concerning the pedagogical proposal of Environmental Education.
\end{abstract}

Keywords: Environmental education; Paper reuse; Rural education.

* Aluna de Mestrado da Universidade Federal do Pampa (UNIPAMPA), Campus Uruguaiana - RS, Brasil. E-mail: francisganzerla@gmail.com ** Aluna de Mestrado da Universidade Federal do Pampa (UNIPAMPA), Campus Dom Pedrito - RS, Brasil. E-mail: fernandatarouco92@gmail.com *** Mestrado. Universidade Franciscana (UFN), Santa Maria - RS, Brasil. Brasil. E-mail: anadesordi@gmail.com

**** Professora da Universidade Federal do Pampa (UNIPAMPA), Campus Dom Pedrito - RS, Brasil. E-mail: aniaramachado@unipampa.edu.br ***** Professora da Universidade Federal do Pampa (UNIPAMPA), Campus Dom Pedrito - RS, Brasil. E-mail: cadidjacoutinho@unipampa.edu.br 


\section{Introdução}

Há milhões de anos, o homem vem explorando os recursos oferecidos pela natureza para sua subsistência, provocando um certo desequilíbrio ecossistêmico. Essa exploração desenfreada dos recursos naturais gerou consequências negativas à equidade dos ambientes e, consequentemente, ao bem-estar da vida do planeta (COUTINHO, 2017).

No contexto ambiental, um dos fatores mais pertinentes é o crescimento do pensamento humanista, pela consequente discussão e atitudes relacionadas ao meio ecológico. Com isso, "a evolução das questões ambientais não tem ficado apenas nas esferas ambientalistas, acadêmicas ou governamentais" (MIRANDA et al., 2019, p.5). Revela-se que, aos poucos, a questão vem ganhando espaço na sociedade e gerando grandes polêmicas e discussões pelas práticas de exploração e atuação que mostram desequilíbrio ambiental (MIRANDA et al., 2019).

Assim, diante das práticas de exploração, desequilíbrios ambientais são notáveis, a exemplo da diminuição da biodiversidade, proliferação de pragas e vetores, poluição da água, redução de áreas verdes e diminuição da qualidade do ar. Santana et al. (2013, p.60) afirmam que "uma das iniciativas mais marcantes da sociedade foi a institucionalização da Educação Ambiental (EA)", um mecanismo capaz de despertar na população uma consciência crítica de suas ações, assim como a necessidade de preservação do ambiente natural compartilhado por todos os seres (COUTINHO; DOROW, 2014).

O aprofundamento crítico nas discussões referentes à Educação Ambiental é de extrema relevância, principalmente ao ser abordado no âmbito escolar, retratando aspectos do cotidiano e das ações da sociedade em geral. É importante considerar o meio em que o aluno está inserido, estimular seu espírito crítico, para que a Educação Ambiental se efetive como uma prática social que possibilite o enfrentamento da grave crise socioambiental (GUIMARÃES, 2013).

Debater diversas formas de preservação e cuidado com o meio ambiente tem se tornado essencial e uma prática pedagógica que vem ganhando relevância no processo de ensinoaprendizagem. A Educação Ambiental tem se mostrado fundamental pelos seus ensinamentos e práticas de saúde ambiental, possibilitando, por exemplo, o reaproveitamento de materiais e favorecendo a inovação, como é o caso do "Papel Semente" (COUTINHO, 2017).

Trata-se de uma ideia relativamente nova quando desenvolvida de maneira artesanal, que permite o percurso da reciclagem e do descarte sustentável. Transforma o papel, que quando feito recebe sementes, possível de germinação de vegetais após seu uso. O "Papel Semente" se mostra como uma opção de reciclagem que busca gerar desenvolvimento sustentável e influenciar a formação de uma sociedade consciente de suas responsabilidades ambientais e sociais (TENÓRIO et al., 2015).

Neste sentido, a presente atividade refere-se a um relato de experiência de uma proposta pedagógica de Educação Ambiental realizada com alunos da educação básica de uma escola pública do campo de Santana do Livramento/RS, com a produção de "Papel Semente". 


\section{Marcos teóricos da educação no campo}

A vida no campo possui suas especificidades, e uma marcante é a relação dos sujeitos com o solo. O solo traz o sustento, mas também as dificuldades de acesso ao meio urbano, especialmente a escola (BRASIL, 2009).

Deste modo, a educação oferecida à maioria dos sujeitos do campo não pode ser a mesma realizada em centros urbanos, pois em diferentes períodos do ano letivo os estudantes não têm acesso à escola, em vista do solo encharcado e transportes de péssima qualidade. A valorização do campo representa a luta por direitos e democratização do uso do solo, o qual representa a cultura, a educação, visto que no campo está um "público que historicamente viu negada a condição de sujeitos de direitos na educação brasileira" (PICCIN, 2017, p.7).

A origem da escola no campo e sua significação é permeada pelas lutas por igualdade e dignidade, e está relacionada com os movimentos sociais (MÉSZÁROS, 2008; CALDART, 2010; MARTINS, 2013; PICCIN, 2017; COELHO, 2019). De acordo com Martins (2013), ela própria pode ser interpretada como um movimento social, pois é nela que convergem as lutas e adversidades de indivíduos organizados em movimentos sociais.

Muitos são os desafios envolvidos na organização escolar do campo, como formar educadores que possuam vínculos com a comunidade ou relacionados à tomada de decisões e soluções inerentes à rotina da gestão escolar ou, ainda, à elaboração de um currículo que seja congruente com a realidade da vida e do trabalho local (SOUZA; JUVÊNCIO, 2017).

Outro elemento crucial para a educação no/do campo que vale ser elucidado são os marcos regulatórios (CALDART, 2010; MARTINS, 2013), justamente como consequência da luta dos movimentos sociais. A partir dela, pode-se encontrar na legislação itens específicos sobre essa modalidade de ensino, mesmo que em pequena medida.

Isto é reforçado por Caldart (2010) quando trata que as novas práticas educacionais se estabelecem como princípios essenciais para a Educação do Campo, em especial pela atividade pedagógica associada aos Movimentos Sociais, com ânsia de reavivar a tradição de uma educação emancipatória, e assim "educar para formar sujeitos capazes de moldar e intervir na sua conjuntura que move uma investigação, mais próximo da realidade vivida na luta pela construção da Educação do Campo" (SOUZA; JUVÊNCIO, 2017, p.168).

Focalizar um trabalho educativo que permita a Educação Ambiental conduz à reflexão sobre a realidade no campo, de modo que os sujeitos possam posicionar-se criticamente a respeito das questões de seu meio, compreendendo-o e esclarecendo sobre assuntos de suma importância para a vida no campo (COELHO, 2019). De acordo com Bernardes, Matos e Nehme (2013), a crise que envolve o meio ambiente reivindica esse trabalho educativo, que sirva de mediador das atividades humanas e que articule a teoria e a prática.

Nesta perspectiva, a Educação Ambiental emerge como um princípio educativo no sentido de ser elemento crítico e articulador de ideias que visem a concepção de uma educação 
que vai além das fronteiras da sociedade (LOUREIRO, 2004), utilizando-se de "práticas pedagógicas fundadas na interdisciplinaridade, na investigação e que favoreçam a construção da cidadania ambiental" (COUTINHO, 2017, p.15), cujo produto seja uma maior conexão entre os sujeitos e a essência da natureza.

\section{Educação ambiental crítica na formação do sujeito ecológico}

Em suas diferentes conceituações, a Educação Ambiental pode representar um conjunto de ações sustentáveis voltadas para a manutenção do meio ambiente. Tem sua origem marcada pela preocupação dos movimentos ecológicos frente à necessidade de alertar os cidadãos sobre a má distribuição e utilização dos recursos naturais, assim como sua exaustão, buscando-se práticas de conscientização e ações socioambientais equilibradas (CARVALHO, 2012).

O tema vem sendo amplamente discutido nos últimos anos, por se reconhecer a imprescindibilidade da melhoria do planeta. Desse modo, torna-se imperativo que a sociedade saia da sua "zona de conforto" e se mobilize a favor do ambiente que ocupa. É fundamental que haja um equilíbrio entre os interesse da sociedade e a manutenção da natureza e de seu recursos naturais, visto que "o mundo contra o qual a crítica ecológica se levanta é aquele organizado sobre a acumulação de bens materiais, no qual vale mais ter do que ser” (CARVALHO, 2012, p.68).

Portanto, torna-se essencial o cumprimento das premissas da Educação Ambiental, por meio de uma explanação mais ampla e crítica a respeito do importante papel da sociedade na formação de sujeitos ecológicos e integrantes fundamentais das relações sociedade-natureza. Segundo Silva (2012, p.04), "a Educação Ambiental apresenta-se como um elemento indispensável para a transformação da consciência ambiental e pode levar à mudança de valores e comportamentos".

Em vista disso, é de extrema relevância a relação de proximidade da sociedade com o meio, e a Educação Ambiental pode ser o mecanismo promissor no estabelecimento de discussões nas diferentes esferas, principalmente no que tange o contexto educacional, favorecendo a formação de indivíduos envolvidos na prática da preservação ambiental, a composição da figura do sujeito ecológico (CARVALHO, 2012; OLIVEIRA; SILVA, 2013) e a excelência de um sistema social eco sustentável.

Educar para além da sociedade do conhecimento que significa, principalmente, e de forma contundente, elaborar críticas a esse modelo socioeducativo, identificando e analisando os riscos ao orientar uma educação para a cidadania em que há supervalorização do capital financeiro em detrimento da valorização das relações sociais em que se cultivam a austeridade, o trabalho de cooperação, a construção de espaços de participação democrática, a formação ética visando a justiça social e ambiental, o desenvolvimento de uma cidadania crítica e do espírito comunitário (FREITAS, 2011, p.244).

Nesta perspectiva, surge a Educação Ambiental crítica, com o objetivo de incentivar a formação do sujeito crítico, capacitado a realizar observações e reflexões sobre seu mundo 
e interferir nele. Permitir que o indivíduo compreenda a Educação Ambiental de forma crítica, em sua amplitude e complexidade, faz de seus pressupostos balizadores a construção de uma educação e, sobretudo, de uma prática que esteja em sintonia com os anseios de contribuir no processo contra-hegemônico (FREITAS; FREITAS, 2020).

Logo, promover práticas educacionais em Educação Ambiental trazendo exemplos da realidade do aluno, como o "Papel semente", favorece a criticidade e faz com que ele se questione a respeito das atitudes que exerce sobre o meio ambiente. Isto é, a ampla relação da educação com as questões ambientais dá impulso à sensibilização das atitudes exercidas pelos grupos sociais para o desenvolvimento sustentável, com o uso dos recursos naturais disponíveis pelo meio ambiente de forma equilibrada, a fim de se garantir a sobrevivência das gerações futuras (CARVALHO, 2014).

\section{Contexto e detalhamento da atividade}

A atividade proposta de produção de "Papel Semente", conduzida pelas autoras, foi realizada com alunos do ensino fundamental - anos finais e ensino médio - de uma escola pública do campo do município de Santana do Livramento/RS. Cabe destacar o porquê da escola do campo e não rural, pois são termos que envolvem a luta pelo reconhecimento das escolas do campo como espaços formativos, e a escola onde a atividade foi realizada tem como base a formação humanitária e integral dos sujeitos que vivem do e no campo. Ou seja,

\footnotetext{
O campo deixa de ser uma sombra da área urbana, sem visibilidade, sem direito, sem reconhecimento e passa a exigir uma educação que reconheça as especificidades, diversidades, diferenças, culturas, memórias, lutas, histórias, vidas e produção do campo (ALENCAR, 2010, p.211).
}

Para tanto, atividades como "Papel Semente" fortalecem a discussão acerca do reconhecimento das especificidades da escola do campo, ao mesmo tempo que possibilitam romper com o antagonismo campo versus urbano. Cabe destacar, ainda, que a referida atividade reforça uma característica fundamental sobre o papel da escola do campo e, também, da universidade pública quanto à perspectiva da extensão enquanto espaço de formação dialógica e não como extensão de conhecimentos (FREIRE, 2011).

O "Papel Semente" foi inserido como forma de comunicação acerca de algo já significado pelos estudantes e demais sujeitos da escola, pois as sementes e o papel (que costumeiramente iria para o lixo) passam a ter novas funções frente às suas diferentes possibilidades de utilização. Além disso, trazem a oportunidade de aproximar a experimentação em uma perspectiva extensionista.

A experimentação como metodologia no Ensino de Ciências permite que o aluno estabeleça relação entre teoria e prática e também serve como suporte metodológico para 
professores, pois "as atividades experimentais possibilitam ao professor gerar dúvidas, problematizar o conteúdo que pretende ensinar e contribuem para que o estudante construa suas hipóteses" (PARANÁ, 2008, p.72).

Giordan (2009) afirma que tanto alunos quanto professores acreditam que a experimentação é uma metodologia motivadora e que promove, além da interação dos alunos na sala de aula, maior compreensão de conteúdos e conceitos.

Por sua vez, Gonçalves e Marques (2006) expõem algumas dificuldades para que a experimentação seja realizada com mais frequência nas aulas de Ciência. Alguns professores justificam a não utilização pela falta de laboratórios, lugares específicos, equipamentos. Sobre as possibilidades de realizar atividades experimentais em lugares alternativos, Risoto (2013) afirma:

\footnotetext{
Acredito que seja possível realizar experimentos na sala de aula, ou mesmo fora dela, utilizando materiais de baixo custo, e que isto possa até contribuir para o desenvolvimento da criatividade dos alunos. Ao afirmar isto, não quero dizer que dispenso a importância de um laboratório bem equipado na conclusão de um bom ensino, mas acredito que seja preciso superar a ideia de que a falta de um laboratório equipado justifique um ensino fundamentado apenas no livro didático (ROSITO, 2003, p.206).
}

Assim, a promoção da aprendizagem através da experimentação não está diretamente relacionada ao lugar em que será desenvolvida, e sim como será desenvolvida.

Desse modo, a atividade proposta foi guiada a proporcionar o protagonismo do aluno frente ao processo de ensino e aprendizagem, e foi dividida em momentos. No primeiro momento, realizou-se a apresentação da proposta juntamente com a discussão inicial sobre a importância de reutilizar os recursos naturais e modificados pelo homem, pois o "Papel Semente", além do impacto pela inovação e criatividade, é produzido com o diferencial de aproximar conceitos de sustentabilidade. Também foi discutido sobre as possibilidades de utilização do "Papel Semente" por cada participante. Após as primeiras conversas e reflexões, a turma foi dividida em grupos de 3 a 5 alunos. A matéria-prima para a atividade foi o papel já utilizado e descartado pela escola, em seus setores administrativos.

Como primeiro passo da produção do "Papel Semente", cada grupo recebeu papéis que deveriam ser picados para posteriormente serem molhados e triturados (Figura 1). 
Figura 1 - Alunos preparando o papel para a atividade.

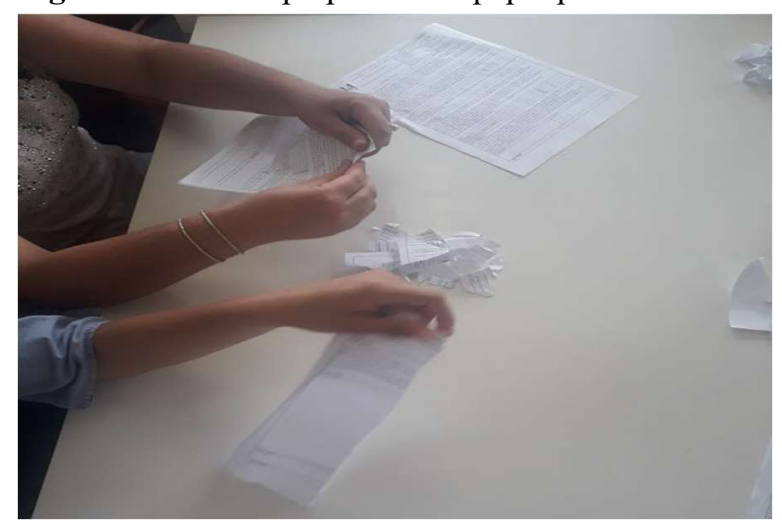

Fonte: Autoras, 2019.

Na segunda etapa da atividade, os papéis já picados foram mergulhados na água e triturados no liquidificador por 30 segundos, tempo suficiente para que a consistência do papel se tornasse pastosa, formando a polpa de papel (Figura 2). Nesse momento, os alunos puderam colorir as polpas de papel através de corantes, o que posteriormente dará cor ao seu "Papel Semente".

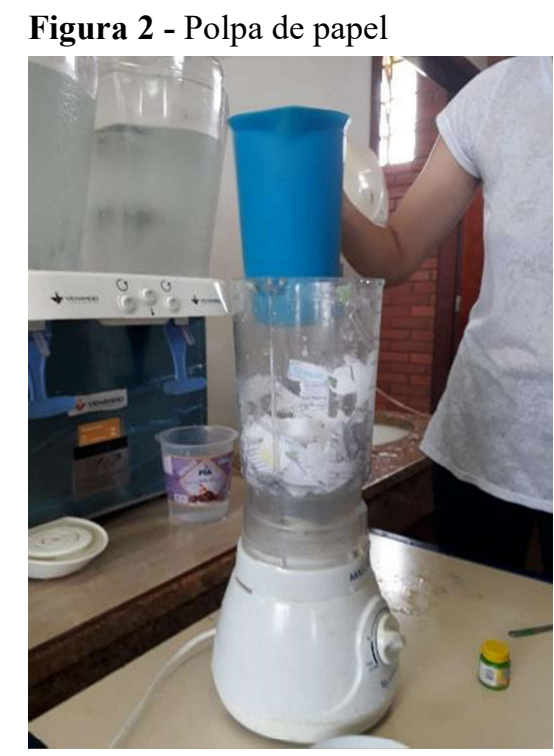

Fonte: Autoras, 2019

Depois do papel já triturado, com a polpa de papel apropriada para a produção do papel semente, foi preparado um recipiente com água, uma peneira do tamanho de um folha de papel sulfite, tecidos tipo TNT (sigla de "Tecido não Tecido") para auxiliar na absorção e 
na modelagem do "Papel Semente", e sementes de fácil germinação (por exemplo, ervas medicinais, temperos e plantas ornamentais).

No recipiente com água, foi posicionada a peneira e, logo em seguida, foi adicionada nesta a polpa de papel (obtida na primeira parte do processo), obtendo-se com isso o formato do papel reciclado. Posteriormente, a peneira foi retirada do recipiente para o escoamento do excesso de água (Figura 3).

Figura 3: Escoamento do excesso de água.

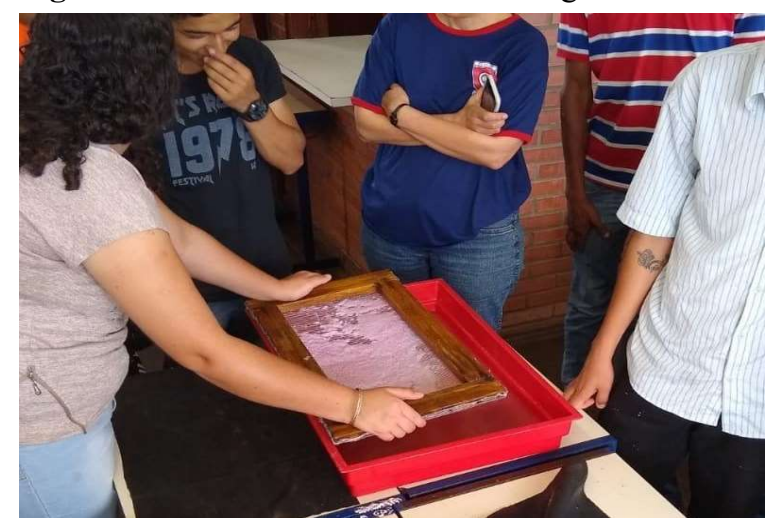

Fonte: Autoras, 2019.

Depois do escoamento inicial, empurrou-se o papel com delicadeza para retirá-lo da peneira e colocá-lo no TNT, onde foi moldado do tamanho desejado e, após, foram adicionadas ao papel as sementes escolhidas, sendo estas agrupadas de forma vertical em diferentes áreas do papel, separadas por tipo de hortaliça para que não se misturassem e para que fosse possível a identificação da semente quando fosse plantada (Figura 4).

Figura 4 - Alunos moldando e acrescentando sementes ao papel.
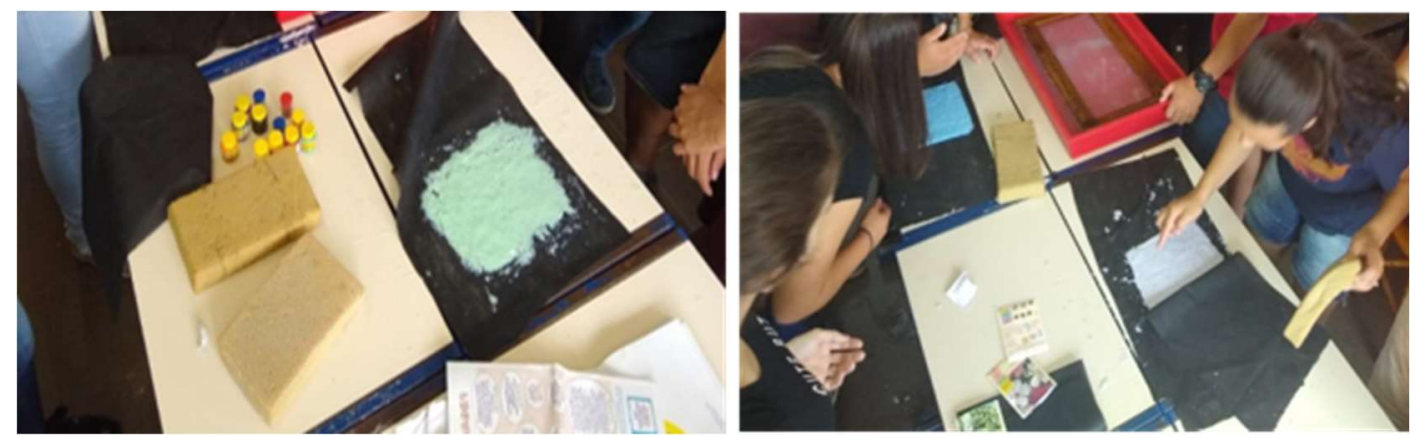

Fonte: Autoras, 2019. 
Com os papéis semente já prontos, foi necessária uma pausa de até 12 horas para sua secagem total e sua utilização para escrita, embalagens, impressões, cartões, entre outras possibilidades.

\section{Análise e discussão do relato}

A Educação Ambiental tem se mostrado fundamental em virtude de seus ensinamentos e práticas de saúde ambiental, possibilitando, por exemplo, o reaproveitamento de materiais e favorecendo a inovação, como é o caso do "Papel Semente".

A proposta pedagógica visou apresentar, por meio de um relato de experiência, uma das maneiras de se preservar o meio ambiente. Para tanto, promoveu-se a Educação Ambiental numa escola pública do campo, com o intuito de sensibilizar e instigar os alunos a se questionarem quais são suas atitudes em relação ao meio ambiente.

A questão ambiental é um tema de grande importância, que precisa estar em constante discussão e transformação em sala de aula (OLIVEIRA et al., 2019), assim como o pretendido neste relato, visando um futuro promissor para as próximas gerações. A respeito da formação de uma população crítica e transformadora, é preciso que cada cidadão tenha consciência do seu papel a ser exercido na sociedade (LIMA, 2009), resultando num processo pedagogicamente complexo e exigente para o professor (ABREU; MIRANDA; CARVALHO, 2019).

Os alunos demonstraram interesse e participação na atividade de produção do "Papel Semente", principalmente por ser uma das formas de destinar papéis usados tanto na escola quanto para uso próprio, os quais não teriam mais utilidade, e também pelas diversas maneiras de uso após sua secagem (como capa de caderno, agenda, cartão de mensagem, bloco de anotações).

Com isso, visando a preservação da natureza e o destino correto de materiais descartáveis, além de fortalecer o diálogo sobre a proteção ambiental, foi possível destacar a possibilidade da reciclagem do papel como fonte de trabalho e renda, aspecto que vai ao encontro do debate acerca das escolas do e no campo, pois acaba sendo mais uma forma de incentivo de permanência no campo.

O envolvimento dos discentes com a proposta também pôde ser percebido por meio de relatos feitos pelos docentes da escola, que afirmam que os alunos do ensino médio, por decisão autônoma e do coletivo de alunos, resolveram replicar a proposta do "Papel Semente" com turmas da educação infantil. Essas informações mostram o protagonismo dos alunos e o engajamento aos aspectos que visam promover a Educação Ambiental no ambiente escolar. 
As questões sobre a proteção ambiental têm sido foco de debates, de eventos científicos e de estudos em diversos níveis acadêmicos abordando temáticas variadas (ASSAD et al., 2011). A reciclagem de materiais, uma das temáticas de destaque, é apresentada em diferentes contextos da pesquisa em Educação Ambiental, principalmente pela vasta quantidade de resíduos sólidos descartados incorretamente (COUTINHO; DOROW, 2014).

Associada a esse debate, inclui-se a ideia destacada anteriormente sobre a permanência dos sujeitos no campo, pois o fortalecimento desse contexto como um espaço de trabalho e vida transcende a perspectiva do camponês como um ser que atua "apenas" com o solo, mas um ser que tem a natureza como sua aliada, a partir da sua preservação.

Estudos mostram que a temática de reciclagem de materiais pode ser um mecanismo para inserção de conceitos (como padrões de consumo, volume do lixo, desperdício, disposição no ambiente e coleta seletiva), estimulando o espírito crítico em relação à exploração dos recursos naturais, e principalmente a formação de uma cidadania ambiental (BASTIANELLO, 2005; ASSAD et al., 2011).

Já a experimentação como ferramenta didática tem a capacidade de auxiliar no desenvolvimento de habilidades, no processo de ensino e aprendizagem, despertando a criticidade do aluno, visando um novo olhar, que vai além da consolidação da teoria (NOGUEIRA et al., 2018). Considerada com grande importância, a investigação de resolução de problemas a partir da prática de experimentação possibilita o despertar da capacidade de formulação e a busca constante de novos saberes.

Ademais, reflete-se como ferramenta no processo de ensino e aprendizagem, mostrando as possibilidades do uso da experimentação em diferentes temáticas, como na Educação Ambiental e em diferentes contextos de aprendizagem, como no espaço formal, não formal e informal. Há, também, a possibilidade de configurar a proposta como uma prática experimental extensionista, contribuindo para a aproximação científica, que vai da extensão universitária para o cotidiano dos estudantes, como uma possibilidade de transmitir esses assuntos de forma compreensível para os educandos e chegar até a sociedade local (LIMA, 2006).

\section{Considerações finais}

A atividade do "Papel Semente" enquanto prática pedagógica pode ser considerada uma proposta dinâmica, que torna viável a inserção de aspectos da Educação Ambiental na sala de aula e fora dela. Ainda, parece indicar a possibilidade do protagonismo da juventude camponesa, visto que, após a atividade, os estudantes do ensino médio realizaram a prática com os alunos de outras turmas. 
Os alunos, a partir de seus discursos durante a realização da atividade, evidenciaram a produção de "Papel Semente" como solução para o reaproveitamento do papel consumido na escola, e uma possível alternativa para a sensibilização e humanização às questões socioambientais.

Através das boas práticas ambientais, pode-se diminuir os danos causados ao meio ambiente. O comportamento e os discursos dos alunos demonstraram grande preocupação e importância para o reaproveitamento do papel, o qual muitas vezes é acumulado e sem destino correto.

Portanto, a prática do "Papel Semente" possibilita ao aluno perceber que há formas de diminuir o acúmulo de resíduos sólidos e destiná-los corretamente, formando, assim, um pensamento crítico, como sujeito ecológico, a favor da proteção do meio ambiente.

\section{Referências}

ABREU, C.R.; MIRANDA, S.C.; DE-CARVALHO, P.S. Análise das Publicações Brasileiras sobre Educação Ambiental com enfoque na temática Mudanças Climáticas. Enciclopédia Biosfera, v.16, n.29, p.1744-1763, jun. 2019.

ALENCAR, M.F. dos S. Educação do Campo e a Formação de Professores: Construção de uma Política Educacional para o Campo Brasileiro. Ciência e Trópico, Recife, v.34, n.2, p.207-226, 2010.

ASSAD, L.G. et al. Reciclagem de papel: uma experiência de ensino, extensão e pesquisa. Interagir: pensando a extensão, n.16, p. 53-57, 2011.

BASTIANELLO, S.F. Desenvolvimento de embalagens a partir de papel reciclado reforçado com fibras naturais: uma proposta ambientalmente amigável. Dissertação (Mestrado em Saúde e Meio Ambiente) - Universidade da Região de Joinville, UNIVILLE, Joinville, 2005.

BERNARDES, M.B.; MATOS, P.F; NEHME, V.G. Educação Ambiental e Agroecologia nas Escolas do Campo. Brazilian Geographical Journal: Geosciences and Humanities research medium, Ituiutaba, v.4, n.1, p.436-447, jul./dez. 2013.

BRASIL. Secretaria de Estado da Educação. II Caderno Temáticos da Educação do Campo. Superintendência da Educação. Coordenação da Educação do Campo. Curitiba: SEED, PR, 2009. 193 p. 
CALDART, R.S. Educação do Campo: notas para uma análise de percurso. In: Coleção Cadernos Temáticos Educação do Campo: Semiárido, Agroecologia, Trabalho e Projeto Político Pedagógico. Santana da Boa Vista, PE, set. 2010.

CARVALHO, I.C. de M. Educação Ambiental: a formação do sujeito ecológico. 6.ed. São Paulo: Cortez, 2012.

CARVALHO, I.C. de M. Educação Ambiental Crítica: nomes e endereçamentos da educação. In: BRASIL, Ministério do Meio Ambiente. Identidades da Educação Ambiental Brasileira. Brasília, DF, 2004.

COELHO, M.G. Por uma educação ambiental do campo. 2019. Disponível em: https://bit.ly/2YEhk3F. Acesso em: 19 abr. 2020.

COUTINHO, C. Por uma "Ciência com consciência": Interfaces da Educação Ambiental e do Ensino de Ciências nos contextos docente, discente e do material didático. Tese (Doutorado em Ensino de Ciências) - Universidade Federal de Santa Maria, Santa Maria, 2017.

COUTINHO, C.; DOROW, T. do C. Papel semente: uma alternativa para inserção da Educação Ambiental na escola. Revista Monografias Ambientais - REMOA, v.14, n.2, p.3183-3191, mar. 2014.

FREIRE, P. Pedagogia da Autonomia: Saberes necessários à prática educativa. 13. ed. Rio de Janeiro: Paz e Terra, 1999.

FREITAS, D. Educação ambiental e o papel do/a professor/a: educar para ale, da sociedade do conhecimento. In: PAVÃO, A.; DE FREITAS, D. Quanta ciência há no ensino de ciências. 1.ed. São Carlos: SciELO-EdUFSCar, 2011. 332p.

FREITAS, A.L.C. de.; FREITAS, L.A. de A. Retomando a educação ambiental crítica a partir dos pressupostos de Paulo Freire e Enrique Dussel. Revista Horizontes, Itatiba, SP, v.38, n.1, 2020.

GIORDAN, M. O papel da experimentação no ensino de ciências. Química Nova na Escola, n.10, p.43-49, 2009.

GONÇALVES, F.P.; MARQUES, C.A. Contribuições pedagógicas e epistemológicas em textos de experimentação no ensino de química. Investigações em Ensino de Ciências, v.11, n.2, p.219-238, 2006. Disponível em:

$<$ http://www.if.ufrgs.br/public/ensino/vol11/n2/v11_n2_a4.htm>. Acesso em: 12 mar. 2020. 
GUIMARÃES, M. Por uma educação ambiental crítica na sociedade atual. Revista Margens Interdisciplinar, v.7, n.9, p.11-22, 2013.

LIMA, G.F.D.C. Educação Ambiental crítica: do socioambientalismo às sociedades sustentáveis. Educação e Pesquisa, São Paulo. v.35, n.1, p.145-163, jan./abr. 2009.

LIMA, K.E.C.; VASCONCELOS, S.D. Análise da metodologia de ensino de ciências nas escolas da rede municipal de Recife. Ensaio: avaliação e políticas públicas em Educação, Rio de Janeiro, v.14, n.52, p.397-412, jul./set. 2006.

LOUREIRO, C.F.B. Educação ambiental transformadora. In: BRASIL. Ministério do Meio Ambiente. Diretoria de Educação Ambiental. Identidades da educação ambiental brasileira. Brasília, DF, 2004.

MARTINS, F.J. Elementos fundamentais da educação do campo. Educere et ducare, v.8, n.15, p.179-198, jan./jun. 2013. Disponível em: https://bit.ly/3b3wVfG. Acesso em: 16 abr. 2020.

MÉSZÁROS, I. A educação para além do capital. Tradução Isa Tavares. 2.ed. São Paulo: Boitempo, 2008. Disponível em: https://bit.ly/35INZXd. Acesso em: 16 abr. 2020.

MIRANDA, B.; MORETTO, I.; MORETO, R. Sustentabilidade: Objetivos Desenvolvimento Sustentável 18 Gestão Ambiental nas Empresas. Programa de Pós-Graduação em Administração e Programa de Pós-Graduação em Economia FEA/PUC-SP, 2019.

NOGUEIRA, B.M.; DAL BÓ, A.; ESTIVALET, A.; DA COSTA, D. Fatores de desinteresse e a experimentação no Ensino de Ciências da Natureza. In: ENCONTRO SOBRE INVESTIGAÇÃO NA ESCOLA: REALIDADES, CONTRADIÇÕES E DESAFIOS, 15., 2018, Porto Alegre. Anais... Porto Alegre, 2018.

OLIVEIRA, L.A. et al. Mapas Conceituais e o Ensino da Educação Ambiental crítica em uma aula de campo na escola. Revista Brasileira de Educação Ambiental, São Paulo, v.14, n.3, p.220-237, 2019.

OLIVEIRA, P.A.; SILVA, C.A. A educação ambiental: As práticas sustentáveis como elemento formativo do sujeito ecológico. In: COLÓQUIO INTERNACIONAL PAULO FREIRE, 7., 2013, Recife. Anais... Recife, 2013.

PARANÁ. Diretrizes Curriculares da Educação Básica para a rede pública estadual de ensino. Ciências. Curitiba: SEED/DEF/DEM, 2008. 
PICCIN, M.A. Apresentação. In: PICCIN, M.A. (org.). Educação do campo, práticas pedagógicas e questão agrária [recurso eletrônico]. Rio de Janeiro: Bonecker, 2017. Disponível em: https://bit.ly/3cauEkb. Acesso em: 16 abr. 2020.

ROSITO, B.A. O Ensino de Ciências e a Experimentação. In: MORAES, R. (org.). Construtivismo e Ensino de Ciências: Reflexões Epistemológicas e Metodológicas. Porto Alegre: EDIPUCRS, 2008.

SANTANA, E.S.; LIMA, E. de C.; SANTOS, B.V. de J. Práticas de educação ambiental projeto: escola e comunidade cuidando do meio ambiente. Caderno de Graduação Ciências Humanas e Sociais, Aracaju. v.1, n.16, p.59-71, 2013.

SILVA, D.G. A importância da educação ambiental para a sustentabilidade. São Joaquim, 2012. Trabalho de Conclusão de Curso, Faculdade Estadual de Educação, Ciências e Letras de Paranavaí-FAFIPA, São Joaquim, Paraná, 2012.

SOUZA, A.C.; JUVÊNCIO, S.M. In: PICCIN, M.A. (org.). Educação do campo, práticas pedagógicas e questão agrária. 1.ed. Rio de Janeiro: Editora Bonecker, 2017.

TENÓRIO, N.S. et al. Utilização do papel semente para a produção de cheiro verde. In: CONGRESSO BRASILEIRO DE QUIIMICA - RECURSOS RENOVÁVEIS: INOVAÇÃO E TECNOLOGIA., 55., 2015, Goiânia. Anais... Goiânia, CBQ, 2015. Disponível em: http://www.abq.org.br/cbq/2015/trabalhos/14/7719-20339.html. Acesso em: 16 abr. 2020. 